\title{
TESTING FOR APOMIXIS IN AN OBLIGATE POLLINATION MUTUALISM
}

\author{
Jonathan T. D. Finch*, Sally A. Power, Justin A. Welbergen and James M. Cook \\ Hawkesbury Institute for the Environment, Western Sydney University, Richmond, New South Wales, Australia
}

Journal of Pollination Ecology, 29(13), 2021, pp 167-178

DOI: $10.26786 / 1920-$

$7603(2021) 644$

Received 6 April 2021, accepted 12 June 2021

*Corresponding author:

j.finch@westernsydney.edu.au

\begin{abstract}
Plants with a small number of specific pollinators may be vulnerable to fluctuations in the availability of those pollinators, which could limit plant reproductive success and even result in extinction. Plants can develop mechanisms to mitigate this risk, such as apomixis. Reproductive assurance mechanisms have been largely ignored in obligate pollination mutualisms (OPMs), that are some of the most specialised of plant-pollinator interactions. Furthermore, although OPMs are often referred to as obligate, this is rarely tested. We performed a flower-bagging experiment to test if the unisexual flowers of Breynia oblongifolia could set fruit in the absence of its highly specialised seed-eating moth pollinators. Surprisingly, many bagged female flowers developed fruits, suggesting apomixis. We therefore conducted a second series of experiments in which we 1) added or excluded pollinators from caged plants; and 2) surveyed a wild population for apomictic reproduction using mother-offspring genotyping. In the absence of pollinators, no fruits developed. In addition, we detected no genetic evidence for apomixis when comparing between mothers and their offspring or between adults in a wild population. We explain the production of fruits in bagged branches by our discovery that $B$. oblongifolia can retain pollinated female flowers over the winter period. These flowers develop to fruits in the spring in the absence of male flowers or pollinators. Our study thus shows that $B$. oblongifolia is unable to produce fruit in the absence of its specialist moth pollinators. Thus, the highly specific interaction between plant and pollinators appears to be truly obligate.
\end{abstract}

Keywords-Breynia, Epicephala, Phyllanthaceae, apomixis, delayed fruit production, dormant pollinated flowers

\section{INTRODUCTION}

In plant-pollinator mutualisms, plants that rely on one, or a closely related group of pollinator species, may be at greater risk of reproductive failure (Waser et al. 1996; Renner 1998). In extreme cases, the loss of a highly specialised animal pollinator could ultimately result in a plant's extinction (Linberg \& Oleson 2001). However, highly specific pollination interactions also have distinct advantages. Plants that are visited by more specialised species of pollinator may be less likely to receive heterospecific pollen (Morales \& Traveset 2008), can have greater pollination efficiency (Scopece et al. 2010) and may show increased gene flow between populations (Scopece et al. 2010; Whitehead et al. 2015). Therefore, there are both important risks and benefits for plants with more specialised pollinators.
Obligate pollination mutualisms (OPMs) include some of the most specialised of all pollination interactions (Kato \& Kawakita 2017). Plants involved in OPMs are generally pollinated by a single species of pollinator, or a few closely related species. Pollinators in OPMs perform pollination because, in addition to depositing pollen, they also deposit their eggs within their host plant's flowers. The pollinated ovules of the host plant become the nursery and sole food source of the developing pollinator larvae. In effect, plants in OPMs sacrifice a proportion of their potential offspring, in the form of seeds, for a highly specialised pollination service. As in other mutualisms, in OPMs both mutualists should be under selection to maximise their own reproductive output at the expense of the other (larvae vs. seeds), creating the potential for evolutionary conflict between partners. How this conflict is resolved can vary widely even 
between closely related OPMs (Kawakita \& Kato 2004; Goto et al. 2010; Furukawa \& Kawakita 2017; Finch et al. 2019) but remains unknown in the majority of interactions. OPMs are known to occur in several disparate plant lineages, with the best known cases involving figs (Cook \& Rasplus 2003), yuccas (Pellmyr 2003), globeflowers (Pellmyr 1989), Silene (Kephart et. al., 2006) and some members of the family Phyllanthaceae (Kawakita 2010), often referred to as leaf flowers.

Despite the apparent risks associated with highly specific pollination interactions, many OPMs have persisted over many millions of years and are geographically widespread. The bestknown example involves $>750$ fig species and their fig wasp pollinators, which have been co-evolving for about $75 \mathrm{MY}$ and have a pantropical distribution (Cruaud et al. 2012). A second and more recently discovered case involves leaf flowers (Phyllanthaceae) and leaf flower moths (Epicephala spp.). In this system, the pollination behaviours currently exhibited by Epicephala moths are believed to have evolved once approximately 20 MYA, with leaf flowers subsequently diversifying to include an estimated 700 plant species across several genera (Kawakita \& Kato 2009; Kawakita et al. 2019). As leaf flower seeds and Epicephala moths are unlikely to be dispersed together, the colonisation of new habitats by these obligate mutualists may be problematic. Despite this, leaf flowers and leafflower moths occur across Asia, Australasia, Oceania and the Neotropics and have repeatedly colonised remote islands across the South Pacific (Hembry, Okamoto and Gillespie, 2012; Hembry et al., 2013).

Redundancy mechanisms, such as longevity, autonomous selfing, vegetative cloning or apomixis may help to explain how plants involved in specialised pollination mutualisms can colonise, persist and diversify across new habitats and regions. Autonomous selfing, or self-pollination, occurs where pollen is transferred between the male and female reproductive structures of a single plant, without the aid of pollinators, and is frequently used by plants that are pollinated by specialised pollinators (Fenster \& Martén-Rodríguez 2007). Apomixis is the development of unfertilised ovules into seeds. Apomixis does not require the transfer of pollen and results in clonal offspring that are genetically identical to the maternal parent
(Nogler 1984; Asker \& Jerling 1992; Hand \& Koltunow 2014). Many plants that display apomixis can do so facultatively, switching from sexual to asexual reproduction depending on the local availability of pollinators (Koltunow et al. 2011). Apomixis is relatively widespread in flowering plants; more than 120 genera in 33 angiosperm families are known to use it via several different mechanisms (Carman 1997; Hand \& Koltunow 2014). However, because only a small proportion of all flowering plants have been checked for apomixis, it is likely that there are many more species that use it than have been identified to date. While redundancy mechanisms and other methods of reproductive assurance have been studied in many plants, they have received little attention in OPMs.

Breynia oblongifolia (Phyllanthaceae) is a widespread Australian leaf flower species that has a pollination mutualism with at least two species of Epicephala moth (Finch et al. 2018, 2019). Although interactions with pollinators in plants such as Breynia are often referred to as obligate, this has very rarely been tested (Pellmyr 2003). Interestingly, $15-30 \%$ of all fruits collected from B. oblongifolia contain no pollinators or evidence of having contained pollinators or other insects (Finch et al 2019). It is unknown if moths always lay eggs within the flowers that they pollinate, as eggs are very small and are often difficult to locate within flowers. To date, no plant species that is involved in an OPM has been shown to be apomictic. However, if $B$. oblongifolia were found to be apomictic, this would have profound implications for our understanding of the ecological stability of the mutualism, as well as how any potential conflict between mutualists may be resolved.

Here we set out to test the hypothesis that $B . o b$ longifolia is an obligate mutualist that requires specialist moth pollination for reproduction. Initially, we used flower bagging experiments to test the ability of B. oblongifolia to set fruits in the absence of pollinators. Surprisingly, many flowers developed fruits during the spring and summer, suggesting the possibility of apomixis. We therefore conducted two follow up experiments in which we 1) experimentally added pollinators to caged plants; and 2) surveyed a natural population of $B$. oblongifolia for evidence of apomictic reproduction using mother-offspring genotyping. In this way, we aim to increase our understanding of how 
plants mitigate against the risks associated with highly specific pollinators.

\section{MATERIALS AND METHODS}

\section{STUDY SPECIES}

Breynia oblongifolia is native to the eastern seaboard of Australia (Atlas of Living Australia 2018). Plants grow to approximately $2 \mathrm{~m}$ tall and bare unisexual male and female flowers that emerge from separate leaf axils (Fig. 1). Female flowers are present throughout the year, but male flowers are only present during the austral spring and summer (Finch et al. 2021). Epicephala moth pollinators are active during the austral spring and summer but absent during the winter (June to September). Many of the female flowers present during the winter contain deposited pollen that was likely deposited during the previous flowering season. However, it is unclear if these pollen grains are in fact viable, and hence further experimentation was required to confirm this (Finch et al. 2021). Female flowers are pollinated by at least two species of $E p$ icephala moth (Finch et al. 2018, 2019). The moth pollinators also lay eggs within the flowers that they fertilize. The pollinator larvae hatch from the eggs and grow by consuming around half the

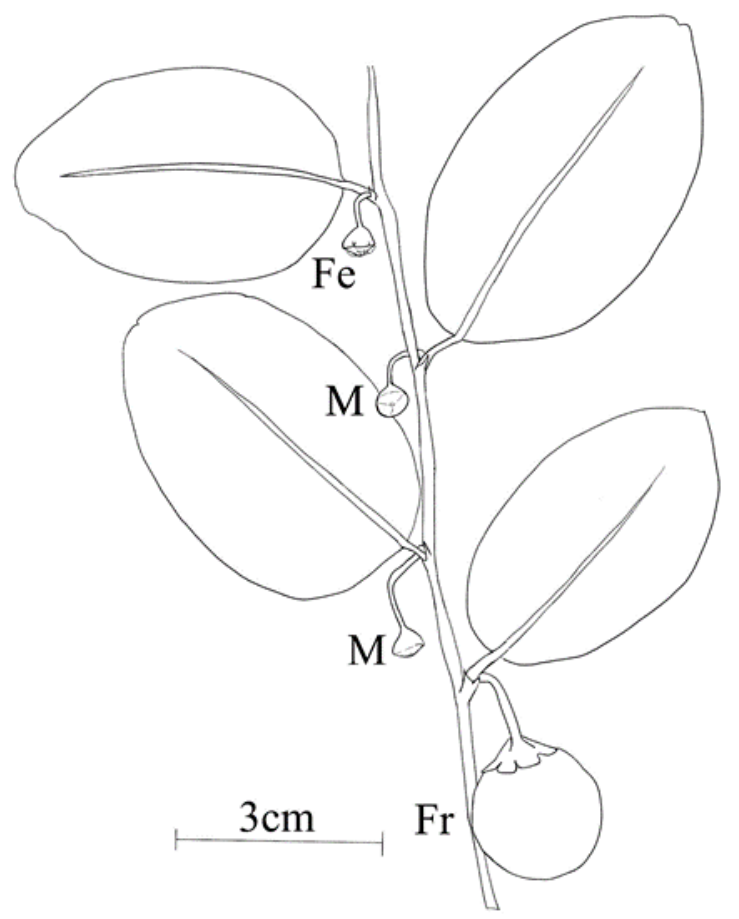

Figure 1. The male flowers (M), female flowers (Fe) and fruits (Fr) of Breynia oblongifolia (Phyllanthaceae). developing seeds in each fruit. However, up to a third of fruits contain no evidence of pollinators. Fruiting is variable between populations, occurring during the austral spring, summer and autumn in response to local rainfall and long duration photoperiods (Finch et al. 2021).

\section{FLOWER BAGGING}

To test the ability of wild plants to set fruit without pollinating moths we conducted a pollinator exclusion experiment at Western Sydney University's EucFACE field site in Richmond, Australia $(-33.6188,150.7368)$. The field site contains a remnant patch of Cumberland Plain Woodland, where a natural population of 200-300 B. oblongifolia forms a large component of the woodland understory. In August 2016, before the emergence of male flowers or pollinators (Finch et al. 2021), we covered eight branches on each of 32 adult plants with fine nylon mesh exclusion bags. Plants $>1 \mathrm{~m}$ in height and $>3 \mathrm{~m}$ apart were chosen randomly by walking two pre-determined transects $(\mathrm{N}=32)$. Any fruits remaining on the branches were removed before the addition of bags. Eight bags were added in pairs around the four cardinal points of each plant canopy and two were then randomly selected for repeat surveys. On one of these branches the bag was left sealed. The bag on the other branch was cut open along the lower seam to allow access to pollinators and thereby serve as a procedural control. For these two branches we recorded the number of mature fruits approximately every two weeks from 5/10/2016 until 17/03/2017. For the six remaining branches, fruits were left to fall off into the bag and were collected and counted after seven months. Of 224 pollinator exclusion bags installed at the start of the experiment, 200 on 32 plants were still attached to their branches after 7 months. The remaining 24 bags were lost to wind, falling branches from the tree canopy or aphid infestations. After collection, fruits were dissected and checked for the characteristic seed herbivory caused by Epicephala moths (Finch et al. 2019). We used generalised linear mixed models (GLMM) to determine if our bagging treatment affected fruit production using the "lmer" function in Lme4 library (v1.1-15) (Bates et al. 2015), specifying a random intercept and slope for date and plant identity. We tested for a significant effect of the experimental treatment using a stepwise deletion method and likelihood ratio tests (Pinheiro \& Bates 
2000; Bolker et al. 2009). All statistical analyses were conducted in $R$ (R Core Team 2021) (V. 3.4.4) using the $\mathrm{R}$ Studio interface (RStudio Team 2016)(V. 1.1.414). All figures included in the manuscript were plotted using ggplot2 (v.0.9.0) (Wickham 2009).

\section{POLLINATOR INTRODUCTION \& EXCLUSION}

In our flower bagging experiment many bagged branches produced fruit. Breynia oblongifolia flowers are unisexual, so the production of fruits on bagged branches is highly unlikely to be due to autonomous selfing. As such, we focussed on the possibility that B. oblongifolia may be facultatively apomictic. To test this, we conducted a second experiment under controlled (cage) conditions to rule out the possibility that pollinated flowers or Epicephala moths were present in the female flowers prior to the addition of the bags, and thus confirm that Breynia is able to produce fruits without pollination (i.e. apomixis). We purchased 150 B. oblongifolia seedlings from a native plant nursery (Indigo Native Nursery, Sydney, NSW). Seedlings had been grown from locally collected seeds until approximately 2 years old $(\sim 0.40 \mathrm{~m}$ tall), in an Australian native plant soil mix, in $40 \times 40 \times 80 \mathrm{~mm}$ plant pots. At this point some of the plants were already producing male and female flowers. As no data exists on the best growth conditions to promote flowering over vegetative growth in B. oblongifolia, we trialled two different re-potting methods. Plants were sorted by height and then placed alternately into two groups from tallest to shortest. One group was re-potted into large $3 \mathrm{~L}$ plant pots using native soil mix (Turtle Landscape Supplies, South Windsor, NSW). The second group was left in the original small pots and soil mix. Re-potted plants in large pots grew larger and had a greater average number of flowers per plant $(14.7, \mathrm{SD}=$ 9.9) than plants that were not re-potted (3.08, $\mathrm{SD}=$ 4.49). Within each group, plants were again sorted by height before being alternately assigned to two experimental treatments; pollinator introduction and no pollinator (control). Plants were numbered and randomly assigned to each experimental treatment.

Prior to the start of the experiment, we carefully examined all the plants and removed female flowers to ensure that no potentially pollinated flowers remained. The plants were placed into $1500 \mathrm{~mm} \mathrm{x}$ $750 \mathrm{~mm} \times 250 \mathrm{~mm}$ nylon mesh cages (Raised
Garden Bed Kit, Roundpoint ${ }^{\mathrm{TM}}$, Australia) in order to exclude Epicephala and other insects. Plants in the small pots were split between two cages, with only one cage receiving pollinators. Plants in the large pots were split between four cages, with two cages receiving pollinators. External openings on the cages were then sealed using duct tape and any remaining gaps were filled with Tanglefoot ${ }^{\circledR}$ (The Scott's Miracle-Gro Company, Marysville, Ohio, USA). As an additional precaution, yellow sticky traps were suspended from the roof of the mesh cage to monitor for insects until the point at which pollinators were introduced. Water was provided by an automated irrigation system for five minutes, twice daily. Plants in the small pots were were given Osmocote ${ }^{\circledR}$ Boost + Feed liquid fertiliser (Scott's, Bella Vista, NSW) on 1/02/2018. Plants in the large pots received the same fertiliser on $1 / 02 / 2018,16 / 4 / 2018$ and $7 / 5 / 2018$. The number of female flowers on each plant, including those that developed into fruits, was counted at the end of the experiment. In both the pollinator introduction and control cage, plants were checked weekly and all male flowers were removed.

Wild Epicephala moths were collected from the EucFACE site whilst ovipositing into female flowers. In this way we ensured that collected moths were likely to be female, carrying pollen, and had previously mated. It was not possible to determine which Epicephala species was collected prior to release as this identification requires destructive sampling (Finch et al. 2018). For plants in the small pots, we collected five Epicephala moths on 15/11/17 and another three moths two weeks later on $29 / 11 / 2017$. For plants in the large pots, we collected 14 Epicephala moths on 4/4/18, splitting them evenly between the two pollinator introduction cages. All Epicephala were released into the experimental treatment during the day, within 24 hours of capture and were not subsequently removed. Fruits were removed at maturity ( $>5 \mathrm{~mm}$ diameter) and placed in plastic pots with mesh-vented lids to allow insect emergence and identification. Following emergence, moths were identified by genital dissection (Finch et al. 2018).

\section{GENOTYPING}

In addition to our pollinator introduction experiment, we used mother-offspring genotyping to determine if some B. oblongifolia seeds are produced via apomixis. In April 2017 we collected 10- 
20 fruits from 27 of the 32 B. oblongifolia plants that had previously been randomly selected at the EucFACE site for the flower bagging experiment, using branches that had not been bagged. The fruits were dissected and sorted into those that did and did not have herbivory damage. As other species of seed herbivore in fruits at the EucFACE site are very rare (Finch et al. 2019), we assumed that all feeding damage was likely to be from Epicephala moths. We reasoned that those fruits that did not exhibit herbivory damage were more likely to be produced by apomixis. Fruits were then dissected, and seeds damaged by herbivory were discarded. Intact seeds were grouped by maternal plant and dried at approximately $15 \%$ relative humidity and $16^{\circ} \mathrm{C}$ for 1-2 weeks. Seeds were then X-rayed on a Faxitron MX-20 (Faxitron X-ray Corporation, Lincolnshire, Illinois) and those seeds without endosperm development were discarded. The Breynia seeds were then planted singly in a sterile seed potting mix (1-part coarse sand, 1-part perlite). Seedlings were germinated at $24^{\circ} \mathrm{C}$ under a 12:12 daylight-night cycle. The seedlings were checked weekly and watered when necessary, to keep the germination medium moist at all times. Germination generally occurred within 10-20 days of planting. At around two months old the seedlings were transferred into a native garden soil mix and grown under glasshouse conditions at $25^{\circ} \mathrm{C}$ and $60 \% \mathrm{RH}$ and watered every 2-3 days.

We genotyped 51 seedlings from 16 adults, 31 seedlings from fruits containing no Epicephala, and 20 seedlings from fruits with Epicephala. In addition, we randomly sampled 27 additional adult plants within the same wild population using the method detailed above. We removed $20 \mathrm{~mm}^{2}$ of leaf tissue from each bush or seedling. The leaf samples were randomised within a 96 well plate and submitted to Diversity Arrays Technology (University of Canberra, Bruce, ACT, Australia) for genotyping using the DArTseq platform (Sansaloni et al. 2011). DArTseq uses restriction enzymes to selectively reduce the repetitive components of a genome prior to Illumina NGS sequencing. The mean depth of coverage is high, at more than 30 reads per locus, to ensure high quality variant calling. Propriety algorithms (Dart Pty Ltd.) were used to remove low quality reads and correct for low quality bases in singleton reads. Propriety software was then used for variant calling and quality filtering (version DArTsoft14).
Diversity Arrays Technology returned a dataset of 8907 loci for all 94 sequenced individuals. Our quality control procedure comprised three steps. The DArTseq service providers use technical replicates of multiple samples to create a "reproducibility score" for each locus. We removed all loci with a "reproducibility score" of less than $96 \%$ and all individuals in which $20 \%$ or more of loci were missing. Of the 6223 remaining loci, we further removed all of those with more than one single nucleotide polymorphism (SNP) per locus. Consequently, even after stringent filtering and quality control, a very large number (4444) of loci were available for our analysis for all 94 sequenced individuals. Loci were recorded as homozygous, heterozygous or missing.

We used the R Package Related (Pew et al. 1999; Wang 2011) to calculate coefficients of relatedness (r) between seedlings and mothers. The r-coefficient between mothers and seedlings produced by apomixis should be equal to one. The same method was used to calculate $r$ between all pairs of adults in the EucFACE population. We hypothesised that if apomixis was occurring, seedlings from fruits without Epicephala would have r-values equal to one, whilst r-values from seedlings resulting from sexual reproduction would be equal to 0.5. Furthermore, any adults in the population that were the clonal offspring of another adult should also have an r-value of one. We used the "compareestimators" function in the same package to determine the best relatedness estimator for our allele frequencies (Wang 2011). In this instance the best estimator was Quellergt (Queller \& Goodnight 1989). The Perm package (Fay \& Shaw 2010) was used to perform a two-sampled permutation test on the relatedness coefficients estimated by Related. We used a Welsh's t-test to test for differences in the proportion of seeds filled with endosperm and the germination rate between seeds with and without feeding damage.

\section{RESULTS}

FLOWER BAGGING

Both bagged and open branches produced fruit. Fruit production primarily occurred in the spring (Nov-Dec) and late summer (March-April) (Fig. 2B). Fruit production on open branches (control) was significantly greater than on bagged branches $\left(\chi^{2}=10.10, \mathrm{DF}=1, \mathrm{P}<0.01\right)$. Although bagged 


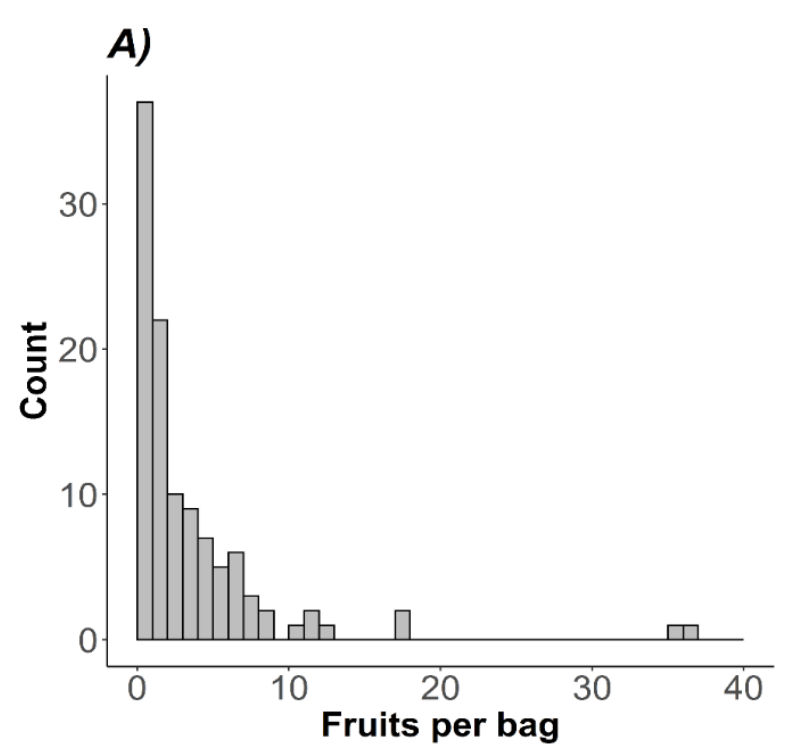

B)

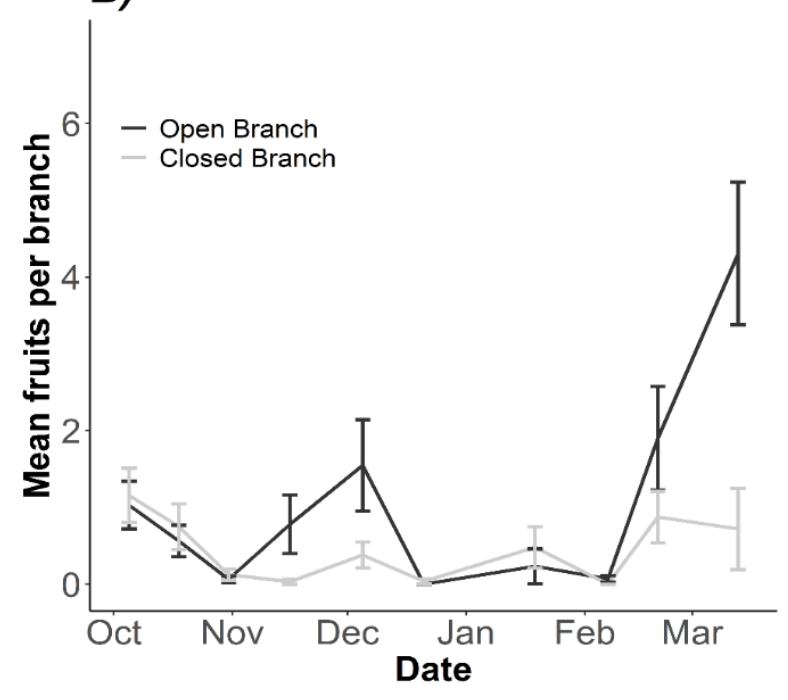

Figure 2. A) Histogram of the number of fruits produced per branch for branches fitted with pollinator exclusion bags ( $N=190)$; ) Mean fruits per branch ( $\pm S E$ ) in branches fitted with pollinator exclusion bags (closed branch) vs control branches fitted with bags that were cut open to allow access by pollinators (open branch).

branches produced fewer fruits than open branches, fruit production occurred in parallel across both treatments, and fruit production was still occurring up to seven months after the addition of pollinator exclusion bags (Fig. 2B). Of the 200 bagged branches, 152 produced a total of 453 fruits (Fig. 2A), with an average of 2.98 fruits per branch $(\mathrm{sd}=4.7)$. These fruits produced an average of 2.4 seeds, which is lower than wild collected fruits (5.1 seeds per fruit) (Finch et al., 2019). Fifteen of the 32 bagged plants were found to have fruits that showed damage characteristic of seed feeding by Epicephala larvae, suggesting that Epicephala pollinators were present in the female flowers prior to the addition of the bags in the winter of 2016.

\section{POLLINATOR INTRODUCTION \& EXCLUSION}

Caged Breynia plants that did not receive pollinators did not produce fruits, whilst plants that received pollinators produced many mature fruits (Fig. 3A). In the small pots, 13 of the 36 plants in the pollinator introduction treatment produced a total of 31 mature fruits. One plant in the pollinator exclusion treatment initiated fruit development but the two developing fruits on that plant abscised before maturity, when approximately $3 \mathrm{~mm}$ in diameter. Amongst the 31 fruits that developed to maturity, 23 exhibited damage from Epicephala seed herbivory. Epicephala moths, which were all sp. A (Finch et al. 2018) were recovered from 12 of these fruits. The remainder of the Epicephala likely emerged prior to fruit collection.

Amongst the Breynia plants that were re-potted into large pots, those that received pollinators produced a total of 231 fruits (mean $=6.41$ fruits per plant, $S D=10.6$ ) from $35 / 36$ plants (Fig. 3B). Approximately half of the fruits $(\mathrm{N}=118)$ showed evidence of seed herbivory and 31 Epicephala were taken after emergence from the collected fruits, most of which (21) were Epicephala sp. B. The mean number of female flowers was the same between treatments in both the small $(\mathrm{T}=-0.70, \mathrm{DF}=66.31$, $\mathrm{P}=0.88)$ and large pots $(\mathrm{T}=-0.15, \mathrm{DF}=68.9, \mathrm{P}=$ 0.4863).

\section{GENOTYPING}

In total, we collected 933 seeds from 27 plants. Of those seeds, 441 came from fruits with Epicephala (26 plants) and 492 were from fruits without $E p$ icephala (24 plants). The mean percentage of seeds with endosperm development (i.e. those that appeared to be viable) was $64 \%$ but this was highly variable between plants $(\mathrm{SD}=27 \%)$. Fruits with $E p$ icephala had a smaller proportion of seeds with endosperm development than those without $(\mathrm{T}=$ 2.50, $\mathrm{DF}=47.9, \mathrm{P}<0.05)$. This is most likely explained by larvae consuming filled seeds and leaving a greater proportion of unfilled, undamaged seeds. In the germination trials, we sowed 350 seeds from fruits with Epicephala herbivory and 209 seeds from fruits without herbivory. The germination rate was low (only 51/559 germinated) and highly variable between plants (mean $=8 \%, \mathrm{SD}=$ 

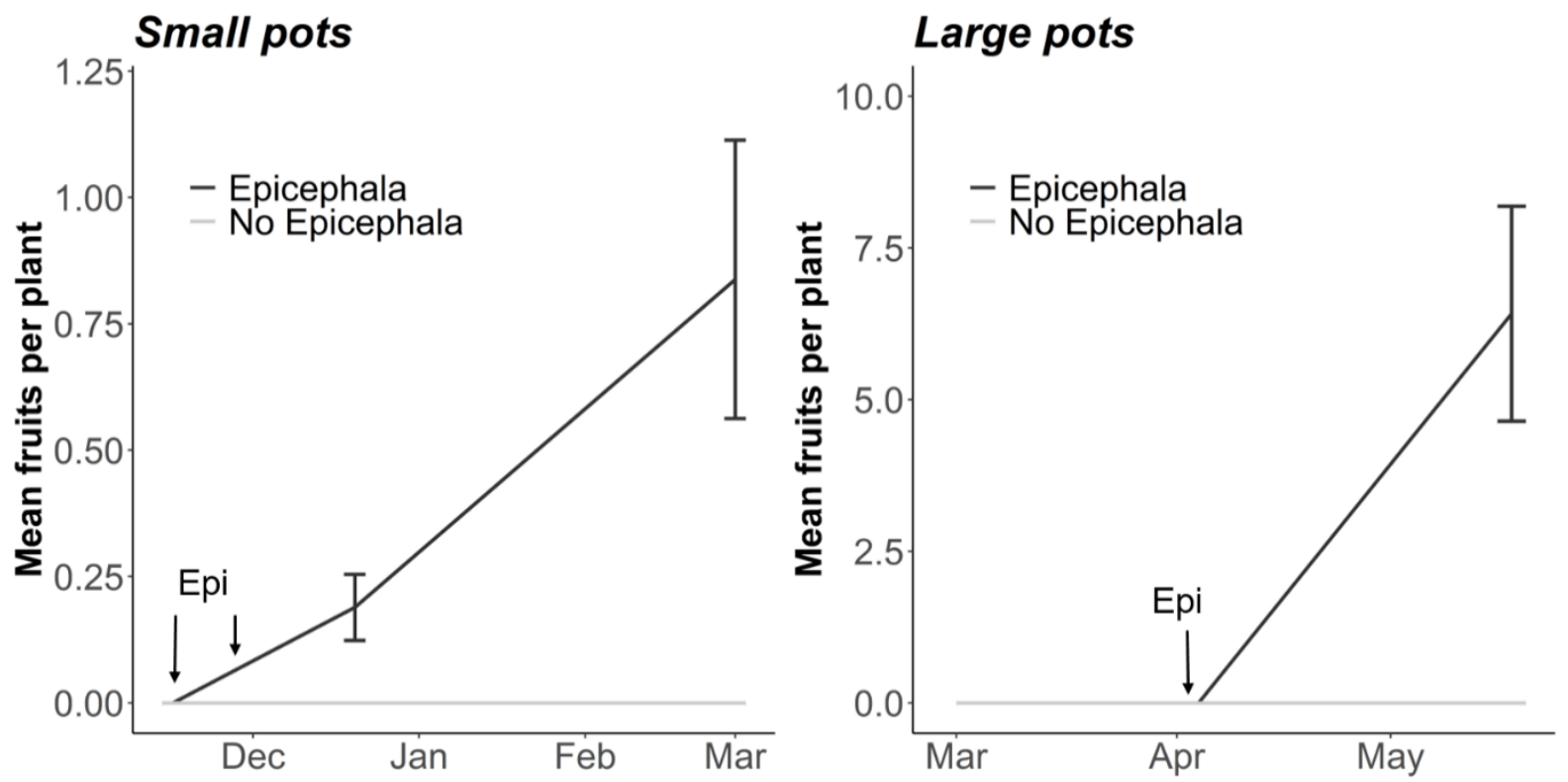

Figure 3. Mean number $( \pm \mathrm{SE})$ of mature fruits per plant in two independent replicated trials (small and large pots) grown with $(\mathrm{N}=36)$ and without Epicephala pollinators $(\mathrm{N}=36)$. Small pot and large pot replicates were included to maximise the likelihood of flowering in young plants (see methods). The date of Epicephala moth introductions are shown (Epi).

$17 \%)$. For $16 / 27$ plants, no seedlings germinated. There was no significant difference in germination between seeds that did and did not come from fruits with Epicephala feeding damage $(\mathrm{T}=0.96, \mathrm{DF}$ $=36.64, \mathrm{P}>0.05)$.

Analysis of the DArTseq data revealed no significant difference in relatedness coefficients $(r)$ between mothers and seedlings from fruits with and without Epicephala ( $\mathrm{Z}=0.22, \mathrm{P}=0.82$ ) (Fig. 4). The mean $r$ values were $0.372(S D=0.053)$ for seedlings from fruits with Epicephala and $0.376(\mathrm{SD}=0.066)$ for seedlings from fruits without Epicephala. No seedling-mother relatedness coefficients from either of these groups approached a value of 1 that might suggest apomixis (Fig. 4). Furthermore, the mean relatedness coefficient between adults within the genotyped population was $-0.024(\mathrm{SD}=$ 0.11 ) and no coefficients exceeded 0.5 , suggesting no evidence of apomixis in the broader adult population.

\section{Discussion}

In this study, we set out to test the hypothesis that Breynia uses apomictic reproduction as a method of reproductive assurance. Although we found no evidence to support the existence of apomixis, we believe we may have identified other traits that act to reduce the likelihood of reproductive failure. Flowering and fruiting in $B$. oblongifolia is highly dependent on local rainfall (Finch et al. 2021), which is highly variable in Australia (Nicholls et al. 1997; Risbey et al. 2009). Retaining pollinated flowers is likely to make $B . o b$ longifolia much less vulnerable to fluctuations in rainfall by allowing Breynia to reproduce when environmental conditions are most suitable, regardless of the co-occurrence of its highly specific pollinators (Finch et al. 2021). As such, we believe that retaining pollinated flowers likely acts to reduce the likelihood of reproductive failure in B. oblongifolia.

\section{GENOTYPING}

We used mother-offspring genotyping to look for genetic evidence of apomixis in a natural population. Estimated relatedness coefficients ( $r$ ) between mothers and their apomictic or clonal offspring should be about 1 (Lynch \& Ritland 1999), while those between mothers and sexually produced offspring should be about 0.5 . In our study, the mean relatedness coefficients between mothers and seedlings from fruits with and without Epicephala was approximately 0.37 and the highest individual $\mathrm{r}$ value identified was 0.52 , so clearly there is no genetic evidence for apomixis. Instead, although the observed $r$ values between parents and offspring were lower than 0.5 , we believe that 


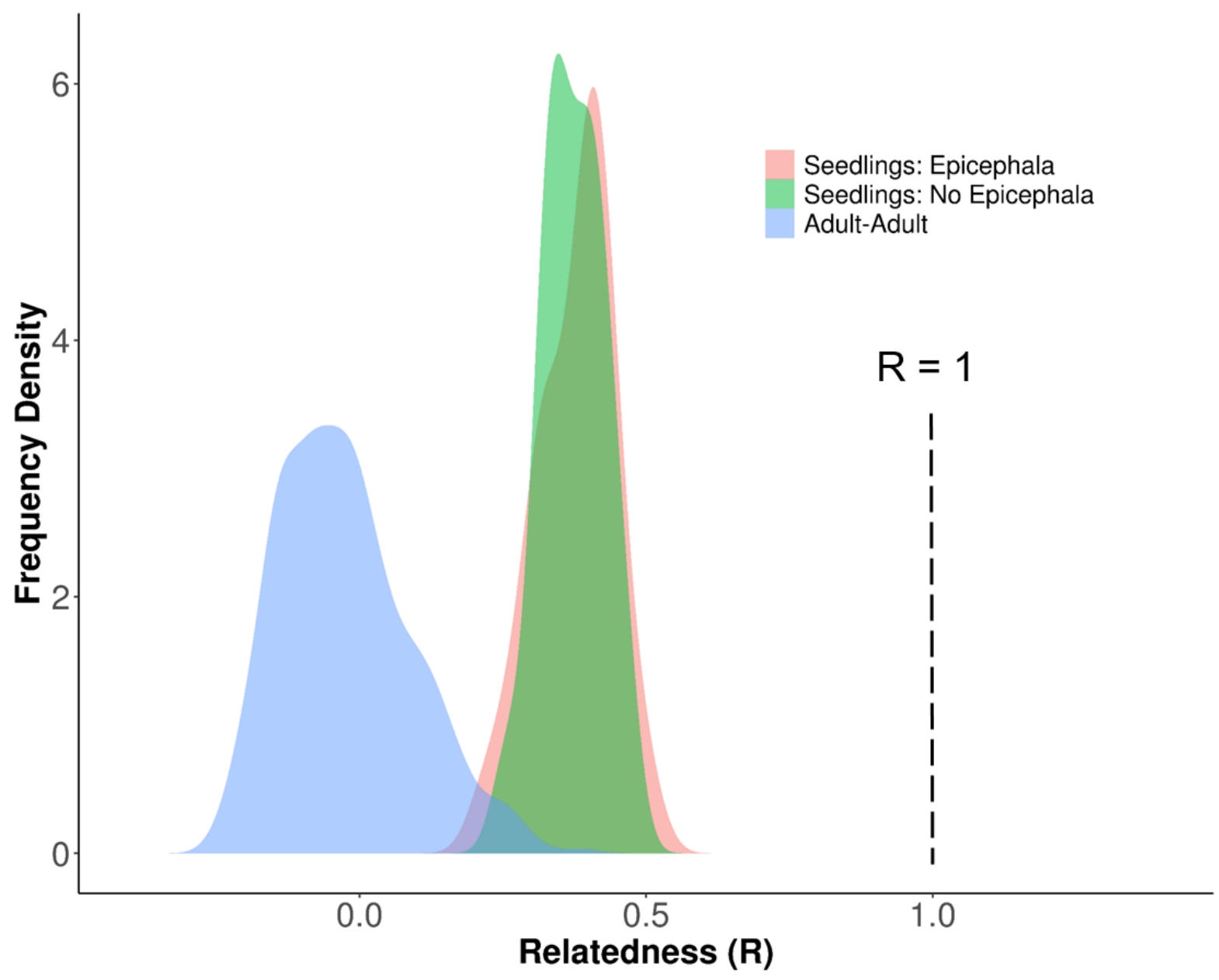

Figure 4. Frequency density function of pairwise relatedness coefficients $(r)$ between B. oblongifolia mother and seedlings from fruits that contained Epicephala $(\mathrm{N}=20)$, didn't contain Epicephala $(\mathrm{N}=31)$ and between randomly chosen adults in the population (Adult, $N=43$ ). The dashed line denotes the expected values of $r$ under apomictic reproduction.

the mean value of $\sim 0.37$ is consistent with a parentoffspring relationship and that all 51 genotyped seedlings probably result from sexual reproduction via pollination. The lower than expected $r$ value may relate to the allele frequencies used to estimate population parameters. Closely related individuals within a single isolated population may have few rare or unique alleles, which could result in an underestimation of the coefficient of relatedness (Wang 2014). The inferred presence of few rare or unique alleles suggests that the $B . o b$ longifolia population at EucFACE may be reproductively isolated. According to the Atlas of living Australia (Atlas of Living Australia 2018), there are up to ten documented records of $B$. oblongifolia within $1-5 \mathrm{~km}$ of the EucFACE population. Epicephala moths have repeatedly colonised oceanic islands and are clearly able to disperse over the relatively small distances discussed here (Hembry et al. 2012). However, it is unknown how frequently Epicephala moths make movements between host plant populations and if pollen is carried when they do so. Our data suggest that Epicephala dispersal may occur relatively infrequently, or perhaps, that dispersing moths rarely carry pollen between Breynia populations. In addition to low relatedness values between parents and offspring, when we calculated relatedness between all 43 randomly sampled adults within the EucFACE population, we did not detect any $r$ values greater than 0.5 . As such we found no evidence of apomixis at the EucFACE site in a large sample of genotyped adults or their seedlings.

\section{DORMANT POLLINATED FLOWERS}

Initially, we conducted a bagging experiment in a wild population of B. oblongifolia to look for evidence of apomixy. In our experiment, bagged 
branches produced fruit for up to seven months after pollinators had been excluded (Fig. 2). We believe that the production of fruit on bagged branches is explained by the recent discovery that B. oblongifolia can retain previously pollinated female flowers over the winter period (Finch et al. 2021). In the initial bagging experiment, we made no attempt to remove female flowers prior to bagging. It is likely that many of the female flowers present on the bagged branches had previously been pollinated, although we were not aware of it at that time (Finch et al. 2021). This also explains why many bagged fruits contained evidence of feeding damage by pollinator larvae. To test our explanation, we conducted a second experiment under controlled (cage) conditions to rule out the possibility that pollinated flowers were present in the female flowers prior to the addition of the bags. We ensured that all flowers present prior to the beginning of the pollinator introduction and exclusion experiment were removed. With this precaution, no flowers developed to fruits in the pollinator exclusion treatment. Future studies should take note of this phenomenon and, where applicable, take precautions to exclude the possibility of pollinated but "dormant" flowers when looking for evidence of apomixis. As such, in accordance with all the available evidence, the production of fruits on bagged branches is best explained by $B$. oblongifolia retaining previously pollinated flowers and not by apomixis.

Our study thus confirms that B. oblongifolia is unable to produce fruit in the absence of pollinators. It is possible that invertebrates other than $E p$ icephala may also contribute to pollination in B. $o b$ longifolia. Indeed, some Breynia species are known to produce nectar (Kawakita \& Kato 2004), which could attract alternative pollinators, but nectar production has not been confirmed in B. oblongifolia. Gall midges (Clinodiplosis sp.: Cecidomyiidae) have been reported to carry very small amounts of Breynia pollen and may contribute to pollination in some Breynia species when foraging for nectar (Kawakita \& Kato 2004). That said, in several hundred hours of observation we did not observe any pollinators other than Epicephala visiting flowers in $B$. oblongifolia at four separate field sites during the day or night (Finch et al. 2018, 2019, 2021). We conclude therefore, for B. oblongifolia at least, pollination by insects other than Epicephala seems unlikely. Thus, the interaction between B. oblongifolia and its Epicephala pollinators appears to be truly obligate.

\section{DIAPAUSING POLLINATORS}

The retention of pollinated flowers is not the only mechanism in this system that appears to limit the impact of environmental unpredictability on the mutualism. In B. oblongifolia, Epicephala moths diapause as eggs within female flowers throughout the winter and possibly at other times of the year (Finch et al. 2021). Indeed, this explains why many fruits in our bagging experiment showed evidence of seed herbivory. In B. oblongifolia, flowering and fruit production is strongly influenced by rainfall and photoperiod (Finch et al 2021). Epicephala develop within growing fruits, emerging and pupating to adults with the appearance of flowers. Pollination and egg laying in virgin female flowers then occurs, initiating the next cycle of fruit and moth reproduction (Finch et al. 2021). In this way, egg diapause appears to promote the synchrony of plant and pollinator lifecycles. This is likely to be particularly important in south eastern Australia, where rainfall is highly variable between years (Nicholls et al. 1997; Risbey et al. 2009). Furthermore, Instead of developing directly to adults, Epicephala moths are also capable of diapausing as pre-pupal larvae for over a year (Finch et al. 2021). Only a small fraction of moths appear to enter into pre-pupal diapause, but it is hypothesized to function as a bet hedging strategy against future variations in the abundance of flowers. In this way, pre-pupal diapause appears to promote more stable pollinator populations. As such, pollinated flower retention, egg diapause and pre-pupal diapause likely function to promote both plant and pollinator reproductive success under unpredictable climates.

\section{CONCLUSIONS}

Floral traits that act to increase the window of opportunity for reproduction appear to be important insurance mechanisms in plant species with highly specific pollinator interactions. For example, in some fig trees, high within-tree flowering and fruiting asynchrony allows for increased opportunities for pollen transmission between trees, and probably also results in more stable figwasp populations (Bronstein \& Patel 1992; Cook \& Power 1996; Compton \& McCormack 1999; Gates \& Nason 2012). In addition, in some fig species, female flowers can remain receptive for a few weeks 
to "wait for pollinators" (Khadari et al. 1995). Comparable adaptations are also found in specialised but non-OPM systems. The flowers of certain infrequently pollinated species of orchid can remain open and receptive for at least three weeks and have pollinia that can remain viable for up to seven weeks (Primack 1985; Gregg 1991; Neiland \& Wilcock 1995). As such, floral traits that act to increase the window of opportunity for reproduction, such as floral longevity or retaining pollinated flowers, appear to be important insurance mechanisms in plants will highly specific pollinators (Caitling 1991).

\section{FUNDING}

This study was funded as part of an International PhD Scholarship awarded to JF by Western Sydney University.

\section{ACKNOWLEDGEMENTS}

We would like to thank Marlien van der Merwe and Jason Bragg at the Royal Botanic Garden Sydney (RBGS) for their assistance in analysing the DArtSeq data. We would also like to thank Karen Sommerville, also at the RBGS, for her assistance and training in germinating the Breynia seedlings and for organising the use of the RBGS facilities. Finally, we would like to thank Stephanie Reid for kindly contributing her drawing of B. oblongifolia to this manuscript (Fig. 1).

\section{REFERENCES}

Asker SE, Jerling L (1992) Apomixis in plants. CRC Press, Cleveland, Ohio. [online] URL: https://books.google.com.au/books/about/Apomixis in Plants.html?id=wbeW6 yVJbgC (accessed 10 May 2018).

Atlas of Living Australia (2018) Atlas of Living Australia Website. [online] URL: https://www.ala.org.au/ (accessed 27 July 2018).

Bates D, Mächler M, Bolker B, Walker S (2015) Fitting linear mixed-effects models using lme4. Journal of Statistical Software 67:1-48. [online] URL: http://www.jstatsoft.org/v67/i01/ (accessed 11 May 2018).

Bolker BM, Brooks ME, Clark CJ, Geange SW, Poulsen JR, Stevens MHH, White J-SS (2009) Generalized linear mixed models: a practical guide for ecology and evolution. Trends in ecology \& evolution 24:127-35. [online] URL: http://www.ncbi.nlm.nih.gov/pubmed/19185386 (accessed 11 May 2018).

Bronstein JL, Patel A (1992) Causes and consequences of within-tree phenological patterns in the Florida strangling fig, Ficus aurea (Moraceae). American Journal of Botany 79:41-48.
Caitling PM (1991) A synopsis of breeding systems and pollination in North American orchids. Lindleyana 6:187-210.

Carman JG (1997) Asynchronous expression of duplicate genes in angiosperms may cause apomixis, bispory, tetraspory, and polyembryony. Biological Journal of the Linnean Society 61:51-94. [online] URL: https://academic.oup.com/biolinnean/articlelookup/doi/10.1111/j.1095-8312.1997.tb01778.x (accessed 26 March 2018).

Compton SG, McCormack G (1999) The Pacific Banyan in the Cook Islands: Have its pollination and seed dispersal mutualisms been disrupted, and does it matter? Biodiversity and Conservation 8:1707-1715.

Cook JM, Power SA (1996) Effects of within-tree flowering asynchrony on the dynamics of seed and wasp production in an Australian fig species. Journal of Biogeography 23:487-493.

Cook JM, Rasplus J-Y (2003) Mutualists with attitude: coevolving fig wasps and figs. Trends in Ecology \& Evolution 18:241-248.

Cruaud A, Rønsted N, Chantarasuwan B, Chou LS, Clement WL, Couloux A, Cousins B, Genson G, Harrison RD, Hanson PE, Hossaert-McKey M, JabbourZahab R, Jousselin E, Kerdelhué C, Kjellberg F, LopezVaamonde C, Peebles J, Peng Y, Pereira RA, Schramm T, Ubaidillah R, Van Noort S, Weiblen GD, Yang D, Yodpinyanee A, Libeskind-Hadas R, Cook JM, Rasplus JY, Savolainen V (Vincent) (2012) An extreme case of plant-insect co-diversification: figs and fig-pollinating wasps. Systematic Biology 61:1029-1047. [online] URL: http://researchdirect.uws.edu.au/islandora/object/uws\%3A16517 (accessed 6 March 2017).

Fay M, Shaw PA (2010) Perm: exact or asymptotic permutation tests. Journal of Statistical Software 36:1-34.

Fenster CB, Martén-Rodríguez S (2007) Reproductive assurance and the evolution of pollination specialization. International Journal of Plant Sciences 168:215-228. [online] URL: http://www.journals.uchicago.edu/doi/10.1086/509647 (accessed 10 May 2018).

Finch JTD, Power SA, Elbergen JAW, Cook JM (2021) Staying in touch: how highly specialised moth pollinators track host plant phenology in unpredictable climates. bioRxiv:2021.03.31.437762. [online] URL: https://doi.org/10.1101/2021.03.31.437762 (accessed 6 April 2021).

Finch JTD, Power SA, Welbergen JA, Cook JM (2018) Two's company, three's a crowd: co-occurring pollinators and parasite species in Breynia oblongifolia (Phyllanthaceae). BMC Evolutionary Biology [online] URL: https://bmcevolbiol.biomedcentral.com/articles/10.1186/s12862-018-1314-y (accessed 16 December 2018).

Finch JTD, Power SA, Welbergen JA, Cook JM (2019) A non-pollinating moth inflicts higher seed predation 
than two co-pollinators in an obligate pollination mutualism. Ecological Entomology:een.12754. [online] URL: $\quad$ https://onlinelibrary.wiley.com/doi/abs/10.1111/een.12754 (accessed 28 May 2019).

Furukawa S, Kawakita A (2017) Limiting the cost of mutualism: the defensive role of elongated gynophore in the leafflower-moth mutualism. Oecologia 184:835846. [online] URL: http://www.ncbi.nlm.nih.gov/pubmed/28707111 (accessed 20 September 2018).

Gates DJ, Nason JD (2012) Flowering asynchrony and mating system effects on reproductive assurance and mutualism persistence in fragmented fig-fig wasp populations. American Journal of Botany 99:757-768.

Goto R, Okamoto T, Kiers ET, Kawakita A, Kato M, Toby Kiers E, Kawakita A, Kato M (2010) Selective flower abortion maintains moth cooperation in a newly discovered pollination mutualism. Ecology Letters 13:321-329. [online] URL: http://www.ncbi.nlm.nih.gov/pubmed/20113331 (accessed 17 April 2018).

Gregg KB (1991) Reproductive strategy of Cleistes divaricata (Orchidaceae). American Journal of Botany 78:350-360.

Hand ML, Koltunow AMG (2014) The genetic control of apomixis: asexual seed formation. Genetics 197:441-50. [online] URL: http://www.ncbi.nlm.nih.gov/pubmed/24939990 (accessed 5 March 2018).

Hembry DH, Kawakita A, Gurr NE, Schmaedick MA, Baldwin BG, Gillespie RG (2013) Non-congruent colonizations and diversification in a coevolving pollination mutualism on oceanic islands. Proceedings of the Royal Society B: Biological Sciences 280:20130361. [online] URL: http://www.ncbi.nlm.nih.gov/pubmed/23760638 (accessed 27 March 2017).

Hembry DH, Okamoto T, Gillespie RG (2012) Repeated colonization of remote islands by specialized mutualists. Biology Letters 8:258-261. [online] URL: http://rsbl.royalsocietypublishing.org/content/8/2/258.abstract

Kato M, Kawakita A (Eds) (2017) Obligate Pollination Mutualism, 1st edn. Springer Japan, Tokyo, Japan. [online] URL: https://www.google.com.au/books/edition/Obligate Pollination Mutualism/CmfTDgAAQBAJ?hl=en\&gbpv=1\&printsec=front cover (accessed 7 June 2021).

Kawakita A (2010) Evolution of obligate pollination mutualism in the tribe Phyllantheae (Phyllanthaceae). Plant Species Biology 25:3-19.

Kawakita A, Kato M (2004) Obligate pollination mutualism in Breynia (Phyllanthaceae): further documentation of pollination mutualism involving Epicephala moths (Gracillariidae). American Journal of Botany 91:1319-1325.
Kawakita A, Kato M (2009) Repeated independent evolution of obligate pollination mutualism in the Phyllantheae-Epicephala association. Proceedings: Biological Sciences 276:417-426.

Kawakita A, Sato AAW, Salazar JRL, Kato M (2019) Leafflower-leafflower moth mutualism in the Neotropics: Successful transoceanic dispersal from the Old World to the New World by actively-pollinating leafflower moths. PloS one 14:e0210727. [online] URL: http://www.ncbi.nlm.nih.gov/pubmed/30699166 (accessed 26 March 2019).

Khadari B, Gibernau M, Anstett M-C, Kjellberg F, Hossaert-McKey M (1995) When figs wait for pollinators: the length of fig receptivity. American Journal of Botany 82:992-999. [online] URL: http://doi.wiley.com/10.1002/j.15372197.1995.tb11563.x (accessed 29 April 2020).

Koltunow AMG, Johnson SD, Okada T (2011) Apomixis in hawkweed: Mendel's experimental nemesis. Journal of experimental botany 62:1699-1707.

Linberg AB, Oleson JM (2001) The fragility of extreme specialization: Passiflora mixta and its pollinating hummingbird Ensifera ensifera. Journal of Tropical Ecology 17:323-329. [online] URL: http://www.journals.cambridge.org/abstract S0266467401001213 (accessed 10 May 2018).

Lynch M, Ritland K (1999) Estimation of pairwise relatedness with molecular markers. Genetics 152:1753-66.

Morales CL, Traveset A (2008) Interspecific pollen transfer: magnitude, prevalence and consequences for plant Fitness. Critical Reviews in Plant Sciences 27:221-238. [online]

URL: https://www.tandfonline.com/doi/full/10.1080/073526 $\underline{80802205631}$ (accessed 3 August 2019).

Neiland MRM, Wilcock CC (1995) Maximisation of reproductive success by European orchidaceae under conditions of infrequent pollination. Protoplasma 187:39-48.

Nicholls N, Drosdowsky W, Lavery B (1997) Australian rainfall variability and change. Weather 52:66-72. [online] URL: http://doi.wiley.com/10.1002/j.14778696.1997.tb06274.x (accessed 17 July 2018).

Nogler GA (1984) Gametophytic apomixis. In: Johri BM (ed) Embryology of Angiosperms. Springer Berlin Heidelberg, pp 475-518. [online] URL: http://www.springerlink.com/index/10.1007/978-3-642-69302-1 10 (accessed 10 May 2018).

Pellmyr O (1989) The cost of mutualism: interactions between Trollius europaeus and its pollinating parasites. Oecologia 78:53-59. [online] URL: http://www.ncbi.nlm.nih.gov/pubmed/28311901 (accessed 25 August 2017). 
Pellmyr O (2003) Yuccas, yucca moths, and coevolution: a review. Annals of the Missouri Botanical Garden 90:35-55.

Pew J, Muir PH, Wang J, Ra YRF (1999) related: an R package for analysing pairwise relatedness from codominant molecular markers. Genetics 152:1753-66. [online] URL: $\underline{\text { https://onlineli- }}$ brary.wiley.com/doi/pdf/10.1111/1755-0998.12323 (accessed 21 March 2018).

Pinheiro JC, Bates DM (2000) Mixed-effects models in S and S-PLUS. Springer.

Primack RB (1985) Longevity of individual flowers. Annual Review of Ecology, Evolution, and Systematics 16:15-37. [online] URL: www.annualreviews.org (accessed 17 March 2020).

Queller DC, Goodnight KF (1989) Estimating relatedness using genetic markers. Evolution 43:258-275. [online] URL: $\quad$ http://doi.wiley.com/10.1111/j.15585646.1989.tb04226.x (accessed 21 March 2018).

R Core Team (2021) R: A language and environment for statistical computing. [online] URL: http://www.r-project.org/

Renner SS (1998) Effects of habitat fragmentation on plant-pollinator interactions in the tropics. In: Newbery DM, Prins HHT, Brown ND (eds) Dynamics of Tropical Commuinities. Blackwell Scientific, London, pp 339-360.

Risbey JS, Pook MJ, McIntosh PC, Wheeler MC, Hendon $\mathrm{HH}$, Risbey JS, Pook MJ, McIntosh PC, Wheeler MC, Hendon HH (2009) On the remote drivers of rainfall variability in Australia. Monthly Weather Review 137:3233-3253. [online] URL: http://journals.ametsoc.org/doi/abs/10.1175/2009MWR2861.1 (accessed 17 July 2018).

RStudio Team (2016) RStudio: integrated development for R. [online] URL: http://www.r-project.org/

Sansaloni C, Petroli C, Jaccoud D, Carling J, Detering F, Grattapaglia D, Kilian A (2011) Diversity Arrays
Technology (DArT) and next-generation sequencing combined: genome-wide, high throughput, highly informative genotyping for molecular breeding of Eucalyptus. BMC Proceedings 5:P54. [online] URL: http://bmcproc.biomedcentral.com/articles/10.1186/1753-6561-5-S7-P54 (accessed 23 March 2018).

Scopece G, Cozzolino S, Johnson SDD, Schiestl FPP (2010) Pollination efficiency and the evolution of specialized deceptive pollination systems. 175:98-105. [online] URL: http://www.journals.uchicago.edu/doi/10.1086/648555 (accessed 31 August 2017).

Wang J (2011) Coancestry: a program for simulating, estimating and analysing relatedness and inbreeding coefficients. Molecular Ecology Resources 11:141-145. [online] URL: http://www.ncbi.nlm.nih.gov/pubmed/21429111 (accessed 21 March 2018).

Wang J (2014) Marker-based estimates of relatedness and inbreeding coefficients: an assessment of current methods. Journal of Evolutionary Biology 27:518-530. [online] URL: http://www.ncbi.nlm.nih.gov/pubmed/24444019 (accessed 3 August 2019).

Waser NM, Chittka L, Price M V., Williams NM, Ollerton J (1996) Generalization in pollination systems, and why it matters. Ecology 77:1043-1060. [online] URL: http://doi.wiley.com/10.2307/2265575 (accessed 25 October 2017).

Whitehead MR, Linde CC, Peakall R (2015) Pollination by sexual deception promotes outcrossing and mate diversity in self-compatible clonal orchids. Journal of Evolutionary Biology 28:1526-1541. [online] URL: http://www.ncbi.nlm.nih.gov/pubmed/26079670 (accessed 3 August 2019).

Wickham H (2009) ggplot2: Elegant graphics for data analysis. Springer-Verlag, New York, USA. [online] URL: http://ggplot2.org 